\title{
El giro participativo de la administración: desafíos en la globalización de los presupuestos participativos
}

\author{
The participatory turn in administration: challenges in the participatory \\ budgeting globalization
}

\author{
Ernesto GANUZA FERNÁNDEZ \\ IESA/CSIC \\ eganuza@iesa.cis.es \\ Manuel FERNÁNDEZ GARCÍA \\ IESA/CSIC \\ manufernandez@iesa.csic.es
}

Recibido: 01/02/2012

Revisado: 08/03/2012

Aceptado: 18/05/2012

Disponible on line: 03/08/2012

\section{Resumen}

El presupuesto participativo es una experiencia nacida en Porto Alegre en 1989. Hoy, sin embargo, podemos encontrar experiencias en los cinco continentes. Han trascurrido apenas veinte años y ya podemos hablar de más de 1.500 experiencias repartidas por todos los rincones del mundo. Si hablamos del éxito de un proyecto, sin lugar a dudas, este es uno. El trabajo que presentamos tiene como objetivo contextualizar este proceso, qué ha significado y cómo ha tenido lugar. La primera pregunta que surge es por qué una experiencia local, nacida en una ciudad del sur de Brasil, consigue expandirse por el mundo y asentarse en contextos políticos, culturales y económicos tan dispares. En segundo lugar, nos planteamos qué entendemos por el presupuesto participativo en el mundo. Esto ha levantado innumerables cuestiones sobre la validez y eficacia del presupuesto participativo. El objetivo seria, entonces, poder acercarnos al presupuesto participativo desde una conceptualización que nos permita configurar una guía para comparar y criticar normativamente el desarrollo de estas experiencias, además de plantear la especificidad del presupuesto participativo respecto a otros instrumentos de participación ${ }^{1}$.

Palabras clave: presupuestos participativos, deliberación, inclusión, democracia desde arriba.

\begin{abstract}
Participatory budgeting is an experience born in Porto Alegre in 1989. Today, however, we find experiences in all continents. After 20 years, we can talk about over 1400 experiences spread all over the world. If we talk about the success of a project, this is one. The present work aims at contextualize this process, what it has meant and how it has taken place. The first question that arises is why a southern brazilian experience has been able to spread around the world, in context so different politically and economically. Second, we try then to understand what is participatory budgeting in the world. The aim would be to approach the participatory budgeting in such a way that it allow us to set a basis for comparing and criticizing normatively the development of these experiences and to be able to point out the singularity of participatory budgeting regarding others participatory devices.
\end{abstract}

Key words: participatory budgeting, deliberation, inclusion, democracy from above.

Referencia normalizada: Ganuza Fernández, E., y Fernández García, M. (2012): «El giro participativo de la administración: desafíos en la globalización de los presupuestos participativos». Cuadernos de Trabajo Social, 25(2): 333-343.

Sumario: Introducción. 1. Los desafíos del método Porto Alegre: de la protesta a la propuesta. 2. La globalización del presupuesto participativo y los dilemas de la deliberación en acción. 3. Los presupuestos participativos en perspectiva crítica. 4. Conclusiones: el problema de la autorregulación. 5. Referencias bibliográficas.

${ }^{1}$ Este artículo forma parte de una investigación internacional. Muchos de los argumentos han sido compartidos y debatidos con otros investigadores, en especial Gianpaolo Baiocchi. Este trabajo se enmarca dentro de un Proyecto de Investigación financiado por el Ministerio de Ciencia e Innovación (CSO2009-12020). 


\section{Introducción}

Tratar el tema de los presupuestos participativos significa referirnos a una experiencia que se escribe en tantas lenguas como podamos imaginar (chino, bengalí, albanés, inglés, español, alemán, francés, japonés, coreano, portugués, árabe, etc.), presente en más de 1.500 ciudades repartidas por los cinco continentes (Sintomer et al., 2010). Este viaje ha generado innumerables cuestiones que tienen que ver, sobre todo, con la posibilidad de ver realizados en otros contextos los éxitos alcanzados por la experiencia brasileña (Avritzer, 2006; Baiocchi, 2005; Santos, 2003; Marquetti, 2003). Las dudas creadas han dejado al descubierto las mismas preguntas que provocó la expansión de las prácticas participativas en los proyectos de desarrollo y que ponían ya en cuestión el sentido transformador que habitualmente se había asociado a la participación (Cook y Kathari, 2001). Estas hacían hincapié principalmente en tres problemas: 1) el escaso impacto de las prácticas participativas en las estructuras más influyentes en la regulación de la vida de las comunidades (Mohan, 2001); 2) la relativización de los marcos en los que operaba el poder y, por tanto, la simplificación de las posibilidades de emancipación de las comunidades (Kothari, 2001); y 3) la utilización de la participación como un método técnico de trabajo, más que como un método político de emancipación (Cleaver, 1999).

Ciertamente los estudios realizados sobre los presupuestos participativos han señalado por lo habitual el débil impacto que han tenido sobre las dinámicas de los municipios donde se han implementado (He, 2011; Sintomer y Ganuza, 2011; Novy y Leuboldt, 2005), por más que la propia experiencia se haya configurado, gracias sobre todo a los logros de Porto Alegre, desde una retórica emancipadora. En la mayoría de los casos podríamos confirmar que el presupuesto participativo es periférico dentro de las administraciones, que hay una sobredeterminación técnica de los procedimientos participativos y que el margen de maniobra de los participantes está lejos de las estructuras de poder locales (Baiocchi y Ganuza, 2013).

El trabajo que a continuación presentamos tiene como objetivo contribuir a este debate con el fin de ofrecer una guía crítica que nos permita reconocer los conflictos y las posibilida- des que el presupuesto participativo tiene como una experiencia política innovadora. El trabajo empieza contextualizando su sentido y los arreglos institucionales que ofrece dicho presupuesto dentro de los marcos institucionales vigentes. Seguiremos con el proceso mediante el cual se puede entender de una forma plausible la expansión de los presupuestos participativos por el mundo y qué elementos podemos considerar transversales con el objetivo de plantear unos criterios que ayuden a mejorar y contrastar las experiencias.

\section{Los desafíos del método Porto Alegre: de la protesta a la propuesta}

Dentro de la teoría de la democracia, uno de los problemas cruciales que afronta la modulación del sistema político es definir los procedimientos adecuados que traduzcan las necesidades ciudadanas en normas y leyes que obliguen a todos. Se entiende que en un marco democrático nadie puede seguir una norma si no se siente subjetivamente vinculado a ella, lo que da lugar al principio de autorregulación (Pwrezoski, 2010; Habermas, 1996; Rawls, 1993). La separación entre política y sociedad ha convertido ese problema en una cuestión central, más cuando la ciudadanía reivindica desde abajo mayor transparencia, más influencia y más justicia social (Appadarai, 2004). Si la participación ha sido siempre vinculada al principio de autorregulación, los sistemas políticos modernos se construyeron con la idea de limitar la influencia de la participación directa de la ciudadanía. El sistema representativo no sólo nace como una segunda opción al mito clásico de la autorregulación participativa, sino como una alternativa encaminada a controlar las pasiones humanas, las injusticias previsibles que se derivarían de la participación directa y los sesgos que podrían producirse en las decisiones administrativas. Las instauración de contrapesos políticos, la constitución de una asamblea soberana regida por un diálogo sosegado y reflexivo, así como el control periódico de los representantes mediante elecciones podría garantizar un desarrollo óptimo del sistema político y del principio de autorregulación democrático (Przeworski, 2010).

El desarrollo de la democracia representativa ha levantado, no obstante, dudas acerca del éxito de sus principios autorregulativos. Como 
sugieren Sartori (1988) o Pwrezoski y otros autores (1999) estas dudas puede que sean desajustes del propio sistema (falta de rendición de cuentas, asimetría de la información, oferta de bienes públicos ambivalente), antes que fallas estructurales del proceso de autorregulación. Aun así, aquéllas han favorecido la emergencia de alternativas y ensayos basados en la idea de la participación con el objetivo precisamente de ofrecer más transparencia e imparcialidad en los proceso de autorregulación. La singularidad de los presupuestos participativos en este contexto ha sido la de universalizar un arreglo institucional renovado y directamente inspirado en la justicia y la participación de toda la ciudadanía directamente en la gestión pública.

A diferencia de la tradición plebiscitaria, el presupuesto participativo concibe la autorregulación como un proceso deliberativo (Avritzer, 2006; Baiocchi, 2005; Fedozzi, 2001), más cercano a la teoría habermasiana que a la teoría de la democracia directa o las teorías sobre democracia radical (Mouffe, 1993), aunque con diferencias relevantes. El giro deliberativo (Habermas, 1996) propuso entender la autorregulación política en una acción separada en dos momentos: primero, una deliberación informal fuera de las instituciones y, después, una formalización de ese debate en forma de opinión pública que influiría en las deliberaciones institucionales. La clave de esta doble articulación residiría en los movimientos sociales, que serían los actores responsables de amplificar una demanda en el espacio público con el objetivo de influir a los representantes en el sistema político. Porto Alegre, la marca, cambió este esquema dentro de un marco característicamente deliberativo. Aquello que para el giro deliberativo era un flujo natural (primero deliberación informal y luego estructuración de los debates en el seno de las organizaciones sociales antes de ser transmitidas al sistema político para crear o modificar el derecho positivo que terminará regulando la vida de la ciudadanía), dejó paso a una deliberación formal (vía los procedimientos del presupuesto participativo) en el espacio público y una influencia directa en la gestión política, fundamentalmente vinculada a la definición de una parte de la ley presupuestaria.

Los presupuestos participativos plantean desde este punto de vista un desafío, pues concre- tan las propuestas del giro deliberativo dentro de un entramado institucional participativo. Si hasta ahora entendíamos la participación como un medio de influencia sobre los representantes políticos, el presupuesto participativo propone que los mismos ciudadanos debatan y elaboren propuestas para ser ejecutadas por las administraciones. En términos generales, eso significa pasar de la protesta a la propuesta, siendo la marca distintiva del presupuesto participativo en cualquier parte del mundo (Sintomer et al., 2010). Precisamente las consecuencias que derivan de un escenario propositivo son las que nos pueden ayudar a pensar criterios generales orientados a criticar los presupuestos participativos.

La diferencia entre el principio de autorregulación del giro deliberativo y los presupuestos participativos reside en la articulación que se da entre el debate y la administración. La posibilidad de que la ciudadanía finalmente incida en la formación de la voluntad política bajo el esquema deliberativo dependería de la capacidad de los individuos para tematizar un problema y arrastrar aliados de modo que los actores políticos institucionales se vieran obligados a considerar ese tema en la formación de las leyes, incluido el presupuesto público (Habermas, 1996). Sigue, bajo el procedimiento habermasiano, habiendo una separación radical entre gobernantes y gobernados que precisamente el presupuesto participativo propuso racionalizar. Esto no significará la fusión de los ámbitos político y social, pero formaliza el espacio público desestructurado que sirve a Habermas para apoyar la deliberación en un entramado representativo. En su lugar, el presupuesto participativo tiene como objetivo una traducción racional del proceso comunicativo de abajo arriba, estructurando la deliberación en el espacio público. En vez de dejar esa traducción al amparo de las fuerzas que ciertos grupos pudieran tener para tematizar un problema, lo que no es ajeno a las luchas de poder entre los grupos corporativos y siembra de dudas el proceso de autorregulación político, el presupuesto participativo se propuso institucionalizar ese espacio público dentro de unos procedimientos transparentes que obligan a todo proponente a una manifestación pública de sus intereses. La deliberación, como ideal regulativo, pasaría a ser un elemento impulsado 
por los mismos procedimientos políticos, en lugar de ser un ideal que fluye sólo en el momento en que dos individuos se encuentran y orientan sus acciones al entendimiento (Habermas, 2006). La diferencia descansa en el papel dado a la administración, pues mediante los presupuestos participativos es ella la que organizaría espacios públicos regulados de forma deliberativa. Indudablemente este giro dado por la participación y, por ende, por la administración, ha planteado preguntas similares a las que se hicieron al giro deliberativo por parte de la teoría política (Thompson, 2008; Sanders, 1996): ¿Quién participa en la formación de la voluntad política? ¿Efectivamente pueden todos los ciudadanos «deliberar»? ¿El proceso es imparcial? ¿Son cualificadas y justas las decisiones que emanan del proceso participativo?

\section{La globalización del presupuesto participa- tivo y los dilemas de la deliberación en acción} Para entender bien la globalización de la experiencia de Porto Alegre parece adecuado observarla como una propuesta que facilitó a los gobernantes de otras partes del mundo poner en marcha un proceso de democratización dentro de los marcos institucionales vigentes. Es preciso recordar que el presupuesto participativo nunca fue concebido, en sus orígenes y su posterior difusión, como una alternativa al sistema representativo, sino como un complemento racional a sus principios de autorregulación, articulando la participación directa y una administración representada por gobiernos elegidos electoralmente ${ }^{2}$. Eso ha permitido a muchos gobiernos locales dar una respuesta administrativa a los desafíos puestos por la creciente reivindicación de la ciudadanía (desde abajo) de mayor justicia y transparencia a la hora de gestionar los recursos públicos. Desde este punto de vista, el presupuesto participativo ha sido un complemento que ha permitido a gobiernos europeos atender las demandas de mayor transparencia e implicación de la ciudadanía en la gestión (Sintomer y Ganuza, 2011), ha facilitado a los gobiernos chinos atender las demandas por disminuir la corrupción e introducir mayor transparencia en la administración única del partido a nivel local (He, 2011). Ha permitido al Banco Mundial adoptar un método para favorecer una mejor distribución de los recursos públicos existentes en países y regiones con carencias socioeconómicas estructurales (Matovu, 2006) o ha permitido a las autoridades coreanas mejorar la administración teniendo en cuenta las necesidades y la realidad de los ciudadanos (Songmin, 2009).

Ahora bien, si el presupuesto participativo ha sido un complemento idóneo desde arriba, se abren muchas cuestiones con relación al modo en que las administraciones han operado para llevar a cabo esta experiencia. La marca «Porto Alegre», contrastada internacionalmente, protegida por la imagen del Foro Social Mundial, patrocinada por la ONU, y avalada por académicos y expertos, ha facilitado su adhesión y su circulación por los entes locales. Poco a poco se ha construido esa imagen de la que se desprende una marca asociada a la transparencia de la gestión administrativa, con una lógica de poder transformadora, basada en la participación de la ciudadanía y en la redistribución de los recursos públicos, vinculándose a las ideas sobre la democratización que han circulado durante los últimos años y que reivindicaban una democracia desde abajo, por contraposición a los poderes de las grandes corporaciones o las elites gubernamentales. Además el hecho de que el método Porto Alegre alcanzara éxitos contrastados (Banco Mundial, 2008) ha permitido que este viaje tuviera lugar sin dificultades de legitimidad. En un momento de expansión de la idea de gobernar en red (governance), el presupuesto participativo ha contribuido con un compendio de arreglos institucionales para que la ciudadanía se implique directamente en la gestión pública. No obstante, los estudios hasta ahora realizados sobre las

\footnotetext{
${ }^{2}$ Raúl Pont (2003: 30), alcalde de Porto Alegre durante los años 1996-1999, lo expresaba de la siguiente manera: «Nuestra experiencia ha despertado la atención de sociólogos, parlamentarios, gobiernos, movimientos sociales y publicaciones de otros estados y, principalmente, de países del resto de América y Europa, porque comprenden que esta práctica retoma una de las cuestiones más expresivas de la democracia representativa de los últimos 150 años, que es cómo dar sustancia, legitimidad y vida al principio de soberanía popular sin el riesgo de que la delegación de poder se transforme - como viene ocurriendo en este siglo en la mayoría de los casos - en simulacro de la representación, fraude de la ciudadanía plena o burocratización de los procesos de toma de decisiones»».
} 
experiencias no son muy concluyentes sobre los éxitos alcanzados. Por un lado, hay pocas dudas sobre el débil impacto de las experiencias sobre las administraciones y la vida de los municipios (He, 2011; Allegretti, 2011; Sintomer y Ganuza, 2011; Shah, 2007). El problema es principalmente el lugar que las mismas administraciones conceden al presupuesto participativo en su entramado institucional. En la mayoría de los países ocupa un lugar periférico respecto a los centros de poder y de decisión de las administraciones públicas (Ganuza y Francés, 2012; Bassolli, 2011; Novy y Leuboldt, 2005), lo cual difumina su impacto y reduce la experiencia a una práctica menor dentro de los municipios. Los presupuestos participativos podrían confirmar por eso muchas de las críticas realizadas a los experimentos impulsados bajo la idea de governance y sus intentos por mejorar el proceso de autorregulación descentralizando la gestión mediante nuevos arreglos institucionales (Swyngedouw, 2005). Desde el punto de vista de la administración, la incorporación de la participación se ha hecho sin modificar sustantivamente las formas de gestión, ni la organización de las mismas, lo que ha dejado al presupuesto participativo un campo de operaciones limitado, a menudo asociado más a los valores desprendidos de la cultura de la Nueva Gestión Pública ${ }^{3}$, que a cualquier otro acervo basado en renovar los procesos representativos de los procesos de autorregulación.

Frente a este dilema, Smith (2009) nos llama la atención para que se piense en el presupuesto participativo en relación a las prácticas pasadas, antes que frente a sus promesas incumplidas. Ciertamente el presupuesto participativo implicaría un avance respecto a las prácticas participativas anteriores, al ampliar el sujeto político, instaurar espacios deliberativos y orientar sus procedimientos, al menos, a una toma de postura de la ciudadanía frente a los gastos públicos, cuando no implica una decisión directa por su parte. Sintomer y otros au- tores $^{4}$ (2010) lo señala incluso como uno de los pocos denominadores comunes que podríamos encontrar entre las experiencias en el mundo. Ahora bien, estando de acuerdo con esa hipótesis (Baiocchi et al., 2011; Ganuza y Francés, 2012), no podríamos dejar de plantear el modo en que ha tenido lugar esta democratización del proceso de autorregulación, pues como han señalado otras investigaciones el balance es a menudo amargo (Allegretti, 2011; He, 2001; Talpin, 2011; Ganuza y Francés, 2011; Bassolli, 2011; Baiocchi et al., 2011; Leuboldt et al., 2008). En todos estos trabajos se muestra que el proceso de democratización ha generado resultados ambivalentes.

El riesgo principal que afronta esta democratización es convertir el presupuesto participativo en un simple proceso de revelación de preferencias individuales, tal y como se podría desprender de las rutinas y los objetivos planteados por la Nueva Gestión Pública. Proceso mediante el cual se sustituirá a los actores tradicionalmente encargados de exponer aquéllas (movimientos sociales y políticos), sin contribuir a cualificar esas preferencias dentro de un marco público de gestión. Si no se cualifican las preferencias perdería significado el desplazamiento de los mecanismos anteriores, a su vez que pondría en entredicho la supuesta democratización y su impacto en las estructuras administrativas.

El presupuesto participativo no ha sido ajeno a las necesidades de esta cualificación de las preferencias. En una investigación llevada a cabo en tres ciudades distintas con presupuestos participativos (Porto Alegre, París y Córdoba), la mayoría de sus impulsores precisamente justificaban los nuevos dispositivos en su capacidad para cualificar las decisiones administrativas, sobre todo, al compararlo con los dispositivos participativos anteriores (Ganuza et $a l ., 2012)$. Para ello se apoyan en procedimientos deliberativos, que sugieren la necesidad de crear espacios donde se citen visiones diferentes, donde cada participante pueda tomar la pa-

${ }^{3}$ La OCDE (2001) recomendaba a principios de siglo a sus países miembros el impulso de la participación, incluso la participación directa, para hacer más eficientes las administraciones, ya que favorecerían una alienación más óptima de la oferta pública a las necesidades ciudadanas.

${ }^{4}$ Según este autor, de la idea de un espacio público vertical, basado en una división radical del trabajo político en el que la ciudadanía ocuparía un lugar periférico, el presupuesto participativo traería consigo una idea horizontal del espacio público que daría un papel activo a la ciudadanía en la gestión pública (Sintomer et. al., 2010, p. 8). 
labra libremente y sin coacciones, además de posibilitarse el intercambio de argumentos. No obstante, los presupuestos participativos están lejos de suscitar consenso a este respecto, incluso dentro de un mismo gobierno que los impulsa. Las organizaciones sociales critican notablemente los nuevos dispositivos, pues para muchas no sólo no cualifican las preferencias, sino que además consiguen ocultar uno de los pocos contrapoderes que queda en las ciudades (idem).

Si tenemos en cuenta la articulación política propuesta por el nuevo dispositivo, tendremos que atender el resultado de la estructuración del espacio público y hasta qué punto garantiza un óptimo proceso de autorregulación. Esto se puede abordar analíticamente, por ejemplo, a partir del grado de inclusión o la intensidad deliberativa alcanzadas en el proceso participativo. Talpin (2011) analizó el desempeño deliberativo de los participantes en tres experiencias europeas, concluyendo que todas ellas mostraban un déficit argumentativo en sus dinámicas. $\mathrm{Su}$ conclusión era amarga, aunque planteaba en su crítica los elementos que habían ayudado a mejorar la deliberación: la aparición del conflicto, tras el cual, en un escenario no coercitivo, se favorecía el intercambio de argumentos entre visiones diferentes. Ganuza y Francés (2011) analizaron, por su lado, el problema de la inclusión y la distribución de las oportunidades deliberativas entre los participantes en el seno de las dinámicas asamblearias en ocho experiencias en España. El trabajo desvelaba un sesgo considerable en la participación, lo que dificultaba la presencia de una pluralidad de visiones en los encuentros participativos y proyectaba una imagen de la experiencia muy sesgada ideológicamente, a favor siempre de los partidos que gobiernan. A pesar de que sus promotores justifiquen la experiencia siempre en la transparencia y la pluralidad de los procedimientos (Ganuza et al., 2012), los resultados de la participación revelaban una politización del perfil de los participantes. No obstante, estos sesgos, que coinciden en parte con los detectados por Talpin (mayor presencia de participantes politizados, ideológicamente afines a los partidos del gobierno y con un perfil sociodemográfico de clase media y alta, como ocurre en la mayoría de los procesos participativos) y que pueden explicar la ausencia de conflicto en el seno de las asambleas públicas, se difuminarían al considerar la distribución de las oportunidades deliberativas en el seno de los presupuestos participativos. Allí, los participantes, de forma independiente a su origen, ideología, perfil o habilidad, se implicarían por igual en las dinámicas deliberativas, lo cual nos permite sugerir que, a pesar, de las deficiencias argumentativas de las deliberaciones, el contexto deliberativo sería aceptado por los participantes y facilitaría su implicación por encima de las diferencias entre ellos.

Por último, si entendemos el presupuesto participativo como una parte de la administración (Bassolli, 2011) o como un proceso que invita a una democratización del proceso de autorregulación desde arriba (Baiocchi y Ganuza, 2013), nos parece que no podemos analizar el impacto del presupuesto participativo sin considerar a su vez las repercusiones que tiene en las estructuras de poder administrativo. Esto implicaría hablar del grado de apertura o margen de maniobra de los participantes para pensar, debatir o tematizar problemas en los espacios públicos estructurados. Hasta ahora, el grado de apertura que han revelado las investigaciones sobre los presupuestos participativos no es muy elevada (Sintomer y Ganuza, 2011), obligando al participante a seguir un protocolo que difícilmente se puede modificar. De alguna manera, podríamos decir que los presupuestos participativos no consiguen aún ser inclusivos, pero sí habrían conseguido levantar espacios públicos no-coercitivos que, a pesar de que no concedan un amplio margen de maniobra a los participantes, son aceptados por éstos.

La expansión del presupuesto participativo ha tenido lugar bajo un ideario que se adecua bien a un contexto de desafección política, en el que la implicación de la ciudadanía se torna casi un imperativo. Posiblemente esto haya permitido a las administraciones ofrecer un proceso participativo anclado en el imaginario de la democracia participativa, sin tener que aceptar por ello una transformación de la organización administrativa, sino favorecer una «tímida» democratización de la sociedad civil. Pero esto sólo puede significar mudar los interlocutores sociales y cambiar los conectores habituales con la opinión pública, bajo un dispositivo meramente técnico y orientado a definir cuestiones sin mayor relevancia desde el punto de vista de la vida de las comunidades. El pro- 
blema no es tanto dar ese paso como hacerlo sin cambiar las lógicas administrativas vigentes. Esto nos hace pensar que si los gobiernos locales reclaman la referencia de los presupuestos participativos en el orden de las ideas, reivindicando la experiencia de la ciudad de Porto Alegre (lo que significa hacerse valedores de un modo de gobernar), pero ofrecen un arreglo institucional basado en sus tradiciones políticas, ante la posibilidad de que emerja una nueva palabra vacía de significado político (Leal, 2007) o la posibilidad de que el presupuesto participativo sea una nueva tiranía política de lo correcto (Cooke y Kothari, 2001), parece razonable pensar más detenidamente los factores críticos que nos ayuden a identificar el éxito del presupuesto participativo independientemente de que éste tenga lugar en China o en Inglaterra.

\section{Los presupuestos participativos en pers- pectiva crítica}

Como procedimiento deliberativo, el presupuesto participativo afronta un problema de legitimación al institucionalizar (formalizar y estructurar) el espacio público. Podríamos sugerir que este giro propositivo de la participación plantea problemas de legitimación en dos niveles distintos: 1) la elaboración de las propuestas, que implica el nivel de inclusión y argumentación en los procedimientos participativos y 2) la definición del gasto público en forma de propuestas concretas, que implica el acoplamiento de la deliberación a las decisiones administrativas.

Respecto al primer nivel de legitimación, el presupuesto participativo establece como sujeto político el conjunto de la ciudadanía, lo que ha tenido consecuencias inmediatas como la oposición de los movimientos sociales urbanos a esta experiencia (Ganuza et al., 2012; Baiocchi et al., 2011). No obstante, la idea de contar con toda la ciudadanía no parece azarosa. En tanto el presupuesto participativo pretende legitimar el procedimiento desde el punto de vista de la administración, necesita habilitar espacios de deliberación universales, pues si el proceso de toma de decisiones es directo, el problema de la inclusión (la pluralidad) es vertebral en el marco de una autorregulación democrática. Si las investigaciones más recientes nos desvelan que este proceso de democratización tiene án- gulos oscuros, es porque precisamente las dinámicas establecidas ofrecen respuestas ambivalentes a esta cuestión. Por eso antes de hablar en términos sustantivos de los presupuestos participativos, podríamos valorar críticamente cómo funcionan y se desarrollan teniendo en cuenta el ideal regulativo ofrecido por la teoría deliberativa habermasiana, pues ofrece un elemento contrafáctico desde donde se pueden evaluar los procedimientos que conducen a la democratización de la formación de la voluntad política.

Para Habermas la formación de la voluntad política empieza en el debate que tiene lugar entre los individuos en el espacio público, un debate sostenido en una acción orientada al entendimiento. Este tipo de acción presupone unos principios regulativos, a los que toda persona se inclinaría por el mero hecho de entablar un diálogo, lo que Habermas (2006, p. 88) denomina las condiciones pragmáticas de la comunicación: inclusión (nadie puede estar excluido de participar en una discusión que le interesa), no coerción (cualquiera pueda formar parte en la argumentación y contra-argumentación libremente sin ser objeto de dominación por otros) $\mathrm{y}$ apertura (cada participante puede iniciar y continuar la discusión sobre cualquier tema relevante, incluyendo los procedimientos que reglamentan la discusión). Kapoor (2002) ya interpretó las condiciones pragmáticas de la comunicación de un modo similar al analizar la participación en los proyectos de desarrollo. Ante la posibilidad de que la difusión de la participación se convirtiera en una excusa metodológica para realizar proyectos de desarrollo con fines espurios, Kapoor propuso contrastar los procedimientos participativos empleados en las prácticas de desarrollo con la ayuda de los principios comunicativos habermasianos. De esta manera Kapoor proponía un marco de evaluación que permitía valorar los resultados de un proceso participativo, a partir de los procedimientos que permitían alcanzar aquéllos. Aquí cabría, entonces, hablar de intensidades participativas, de procesos espurios o experiencias exitosas.

Al trasladar este marco crítico al presupuesto participativo, podríamos examinar las experiencias existentes a partir del modo en que aquél estructura el espacio público. Podríamos suponer que un espacio participativo sobre el que una parte de la población no se sienta invi- 
tada por cuestiones ideológicas, no favorecería un procedimiento inclusivo. Igualmente tendríamos que valorar hasta qué punto los participantes se sienten libres para argumentar y si pueden o no abrir debates o discutir las reglas que regulan los mismos procedimientos.

Ahora bien, cualquier proceso de autorregulación no descansa únicamente en la comunicación, lo que nos lleva al segundo nivel de legitimación que apuntábamos (el acoplamiento de la deliberación con las estructuras administrativas). Desde el punto de vista habermasiano las condiciones pragmáticas de la comunicación tienen lugar en un espacio informal, cómo puede ser posible, entonces, llevar estas condiciones a un espacio estructurado y formal desde el que definir el gasto público, ¿cómo se legitiman las decisiones si no son tomadas directamente por los representantes elegidos en las elecciones?; ¿se pueden arbitrar procedimientos que legitimen las decisiones de una forma tan efectiva como lo han hecho los procedimientos de las democracias liberales?; ¿qué ocurre con el control social y político de los gobernantes, el tradicional equilibrio de poderes de las democracias modernas?

El segundo nivel de legitimación plantea la argumentación, no la protesta y la presión, como canal de decisión pública y, por tanto, como proceso de cualificación de las preferencias mediante la cual se acoplaría la deliberación con las decisiones administrativas. Para Habermas, este acoplamiento se produce, sin embargo, mediante un proceso ajeno a la comunicación. $\mathrm{La}$ efectividad de la comunicación residía para Habermas en la generación de decisiones vinculantes, basadas en las pretensiones de validez argumentativas que exponen los participantes en sus diálogos (Habermas, 2006, pp. 89-90). Pero el acoplamiento tiene lugar a través de mediaciones (organizaciones políticas y sociales) que son las que terminarán por configurar el derecho positivo, baluarte moderno de los principios de autorregulación. Porto Alegre planteó una alternativa a esta forma de entender el acoplamiento, partiendo por igual de un entramado deliberativo. Su propuesta pretendió hacer converger en su entramado institucional las condiciones pragmáticas de la comunicación (primer nivel) con un proceso de autorregulación a imagen del procedimentalismo rawlsiano (el velo de la ignorancia).
Los representantes políticos se convierten en los presupuestos participativos en los garantes de la administración, lo que significa que todos los recursos públicos existentes para mantener la administración y sus servicios públicos nunca se ponen a debate. Eso significa dejar fuera habitualmente tres cuartas partes del presupuesto de la administración. Digamos que los representantes políticos se reservan el poder de establecer los límites sobre los que va a tener lugar la deliberación política. Una vez definido esos límites, el presupuesto participativo instituyó en Porto Alegre un procedimiento participativo en diversas etapas a través de las cuales se obtenía como resultado las propuestas ciudadanas. Aquí la legitimación final de los resultados no se derivaba únicamente de los mejores argumentos. El presupuesto participativo instauró un proceso deliberativo de corte habermasiano en la elaboración de propuestas, donde éstas eran valoradas por su razonabilidad en un espacio no coercitivo e igualitario (las asambleas). Pero, los representantes políticos de Porto Alegre, proclives a garantizar la legitimidad del nuevo arreglo institucional desde el punto de vista de la administración, plantearon más procedimientos destinados a proteger la toma de decisiones de influencias no deliberativas. Aquí, se incorporaría el procedimentalismo rawlsiano, pues todas las propuestas tenían que ser valoradas siguiendo criterios técnicos, previamente consensuados por la población, los cuales dotaban a cada propuesta con una puntuación especifica (independientemente de quién planteara la misma). Mediante ellos la administración priorizaba y legitimaba las propuestas ciudadanas surgidas del espacio público formal. Por tanto, la deliberación no sólo se fundamentaba en los principios pragmáticos emanados de la acción comunicativa (inclusión, no coerción y apertura), sino en un arreglo institucional similar al velo de la ignorancia rawlsiano, lo cual ofreció la posibilidad de racionalizar la participación y el proceso comunicativo dentro del sistema político (esto tenía lugar en el Consejo de los Presupuestos Participativos: COP). Además dotaba a los participantes de un instrumento que no dependía de la voluntad de los representantes y mediante el cual el ejercicio del poder podía ser evaluado. Esto nos plantea un reto de cara a valorar los presupuestos participativos, pues además de la intensidad deliberativa, ha- 
bría que examinar la intensidad con que los participantes pueden cualificar sus preferencias y ordenarlas según criterios universales y justos. Solo así podremos entrever el proceso de autorregulación política.

\section{Conclusiones: el problema de la autorre- gulación}

El principal problema que afrontan los procedimientos participativos es su capacidad de regular los actos administrativos. Desde el punto de vista de Habermas eso no es un problema, pues los participantes en un diálogo lo hacen en un espacio informal sin conexión con los procesos de toma de decisiones públicos. Para Habermas el debate público tiene lugar dentro de un proceso en el que rigen los partidos y son éstos los que con más o menos intensidad escuchan e incorporan los debates de la ciudadanía. Esto plantea un dilema respecto a la tradición participativa al vaciar de contenido práctico el debate público. La tradición política se ha forjado alrededor de este ideal, por el cual se ha confeccionado un espacio político en el que la ciudadanía es sustituida por las organizaciones y los debates proposititos son sustituidos por la defensa de intereses parciales. El dilema que afronta el sistema político no es pequeño cada vez que impulsa una decisión administrativa, pues debe justificar su decisión en la pluralidad ciudadana. Pero al no poder acudir a fuentes sagradas o imperativos, debe razonar las decisiones en un supuesto debate ideal, cuyos resultados sean compartidos o, al menos, asumibles desde el punto de vista de cada cual. Se produce una fractura, pues cuando un individuo entra en un debate propositivo, siguiendo las condiciones pragmáticas de la comunicación, debe aceptar al otro y aceptar un proceso de racionalización del debate del que puede derivarse un logro distinto al pensado por uno mismo. En cambio, si solo podemos asumir la defensa de nuestros intereses, el resultado es una derrota de antemano para el que no consiga sacar adelante lo suyo.

La estructuración de este debate mediante procedimientos deliberativos lleva la participación, en cambio, a los problemas habituales de legitimación a los que ha sido expuesta tradicionalmente. Aquí el problema es casi siempre la dificultad de concretar el proceso de autorregulación. La habitual oposición que se ha hecho entre las libertades de los modernos y los antiguos (Condorcet) refleja la aspiración a un proceso de autorregulación más abstracto. El presupuesto participativo, en cambio, ha ofrecido un modo de operacionalizar ese proceso de autorregulación mediante un proceso participativo, creando un procedimiento a medio camino de las condiciones pragmáticas de la comunicación habermasiana y el velo de la ignorancia de Rawls. Este procedimiento permitiría llevar la deliberación de los participantes desde un espacio público estructurado a un foro más reflexivo, evitando caer en los problemas de legitimación que siempre se han atribuido a los procesos participativos. Pero, sobre todo, permitiría acoplar el procedimiento participativo dentro de la administración, mediante un proceso en el que técnicos y políticos tendrían un rol clave para desarrollar el debate público, garantizar la información y el cumplimiento de las reglas de justicia que los participantes se dieran a sí mismos tras el velo de la ignorancia. De este modo, el presupuesto participativo podría ofrecernos un ideal regulativo para evaluar las prácticas democráticas realizadas. Desde aquí, al igual que pasa con los procedimientos representativos, la intensidad con la que los procedimientos instaurados consigan democratizar el debate público y acoplar éste a la administración será siempre criticable.

\section{Referencias bibliográficas}

Allegretti, G. (2011). Los presupuestos participativos en África y en Asia. En A. Falck y P. Paño (eds.), Democracia participativa y presupuestos participativos. Málaga: Diputación Málaga y Unión Europea.

Appadarai, A. (2004). Culture and the Capacity to Aspire. En, Vijayendra Rao y Michael Walton (eds.), Culture and Public Action. Nueva Delhi: Permanent Black.

Avritzer, L. (2006). New public spheres in Brazil: local democracy and deliberative politics. International Journal of Urban and Regional Research, 30 (3). 623-37.

Banco Mundial (2008). Toward a more inclusive and effective participatory budget in Porto Alegre (Informe No. 40144-BR). Washington: World Bank. 
Baiocchi, G. (2005). Militants and Citizens. Palo Alto: Stanford University Press.

Baiocchi, G.,Heller, P. y Silva, MK. (2011). Bootstrapping Democracy: transforming lacal governance and civil society in Brazil, Stanford: Stanford University Press.

Baiocchi, G. y Ganuza, E. (2013), Democracy in motion. Manuscrito inédito.

Bassolli, M (2011). Participatory budgeting in Italy: as analysis of (almost democratic) participatory governance arrangements. IJURR, doi: 10.1111/j.1468-2427.2011.01023.x

Cleaver, F. (1999). Paradoxes of Participation: Questioning Participatory Approaches to Development. Journal of International Development, 11, 597-612.

Cooke, B. y Kothari, U. (eds.) (2001). Participation: The New Tyranny, Londres: Zed Press.

Fedozzi, L. (2005). Perfil Social e Associativo dos Participantes do OP de Porto Alegre. Porto Alegre: UFRGS Editoria.

Ganuza, E. y Francés, F. (2012). El círculo virtuoso de la democracia: los presupuestos participativos a debate. (Manuscrito presentado para su publicación).

Ganuza, E. y Francés, F. (2011). The deliberative turn in participation: the problems of inclusion and deliberative opportunities in participatory budgeting. European Political Science Review. doi:10.1017/S1755773911000270.

Ganuza, E. Nez, H. y Morales, E. (2012). The struggle for the voice: associations against citizens in participatory budgeting. (Documento de trabajo).

Habermas, J. (1996). Between Facts and Norms: Contributions to a Discourse Theory of Law and Democracy. Cambridge: MIT Press.

Habermas, J. (2006) Entre naturalismo y religión. Barcelona: Paidós.

$\mathrm{He}$, B (2011). Civic engagement through participatory budgeting in China: three different logics at work. Public Administration and Development, 31, 122-131.

Kapoor, I (2002).The Devil's in the Theory: A Critical Assessment of Robert Chambers' Work on Participatory Development. Third World Quaterly, 23 (1), 101-117.

Kothari, U. (2001). Power, knowledge and social control in participatory development. En B. Cooke y U. Kothari, Participation: The New Tyranny (pp.139-152). Londres: Zed Press.

Leal, P. (2007). Participation: the ascendancy of a buzzword in the neo-liberal era. Development in practice, 17 (4-5), 539-548.

Leubolt, B; Novy, A y Becker, J (2008).Changing Patterns of Participation in Porto Alegre. International Social Science Journal, 59 (193), 435-448.

Marquetti, A. (2003). Participação e redistribuição: o Orçamento participativo em Porto Alegre. En L. Avritzer y Z. Navarro, A inovação democrática no Brasil. São Paulo: Cortez.

Matovu, G. (agosto,2006). Capacity building for participatory planning and budgeting in Africa. Comunicación presentada en la Conferencia de Ministros de Gobiernos Locales, Maseru (Leshoto).

Mohan, G. (2001). Beyond Participation: Strategies for Deeper Empowerment. En B. Cooke y U. Kothari, Participation: The New Tyranny (pp. 153-167). Londres: Zed Press.

Mouffe, C. (1993). The return of the political. Londres: Verso.

Novy, A. y Leubolt, B. (2005). Participatory Budgeting in Porto Alegre: Social Innovations and the dialectical relationship of State and civil Society. Urban Studies, 42 (11), 2023-2046.

OECD (2001). Citizens as partners. Paris: OECD.

Pont, R. (2003). Democracia, igualdade e qualidade de vida: a experiencia de Porto Alegre. Porto Alegre: Veraz.

Przeworski, A., Stokes, S. C. y Manin, B. (eds.) (1999). Democracy, Accountability and Representation. Cambridge: CUP.

Przeworski, A. (2010). Democracy and the limits of self-government. Cambridge: CUP.

Rawls, J. (1993). Political liberalism. Nueva York: Columbia University Press.

Sanders, L. (1997). Against Deliberation. Political Theory, 25, 347-76.

Sousa Santos, Boaventura de (2003). Democracia y participación, el ejemplo del Presupuesto Participativo. Madrid: Viejo Topo.

Sartori, G. (1988): Teoría de la democracia, Madrid: Alianza. 
Shah, A. (ed.) (2007). Participatory budgeting, Publics Sector Governance and Accountability series, Washington: World Bank.

Sintomer, Y. y Ganuza, E. (2011). Democracia participativa y modernización de servicios públicos: los presupuestos participativos en Europa. Ámsterdam: TNI.

Sintomer, Y., Herzberg, C. y Allegretti, G. y Rocke, A (2010). Learning from the South: Participatory Budgeting Worldwide - an Invitation to Global Cooperation. Bonn: InWEnt gGmbH Capacity Building International, Germany/ Service Agency Communities in One World.

Smith, G. (2009). Democratic Innovations. Cambridge: CUP.

Songmin, A. (agosto, 2009). Korean cases: participatory budgeting in Dong-Ku, Ulsan. Comunicación presentada en la Conferencia Participatory Budgeting in Asia and Europe: key challenges of participation. Hangzou (China).

Swyngedouw, E. (2005). Governance innovation and the citizen: the Janus face of governnace-beyond-the-state. Urban Studies, 42 (11), 1991-2006.

Talpin, J. (2011). Schools of Democracy: How ordinary citizens (sometimes) become competent in participatory budgeting institutions. Colchester: ECPR Press.

Thompson, D. (2008). Deliberative Democratic Theory and Empirical Political Science. American Review of. Political Science, 11, 497-520. 